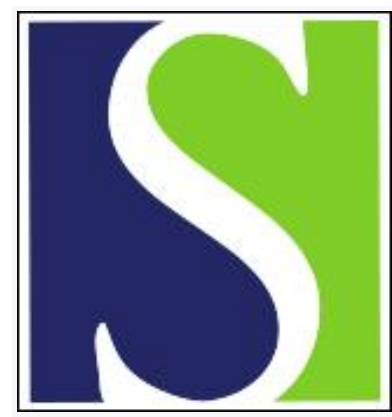

Scand J Work Environ Health 2012;38(4):314-326

https://doi.org/10.5271/sjweh.3306

Published online: 30 May 2012, Issue date: 01 Jul 2012

Implementation of self-rostering (the PRIO-project): effects on working hours, recovery, and health

by Garde AH, Albertsen K, Nabe-Nielsen K, Carneiro IG, Skotte J, Hansen SM, Lund $\mathrm{H}, \mathrm{Hvid} \mathrm{H}$, Hansen ÅM

In this large, longitudinal intervention study on self-rostering, employees changed shift length and timing, but did not compromise most recommendations for acceptable shift work schedules. Positive consequences for recovery and health were observed. The effect could not be statistically explained by changes in actual working hours.

Affiliation: Lersø Parkallé 105, 2100 København $\varnothing$, Denmark. ahg@nrcwe.dk

The following articles refer to this text: 2012;38(4):291-297; 2015;41(4):347-355; 2020;46(4):429-436; 2021;47(6):446-455; 2022;48(3):200-209

Key terms: health; health; healthcare; intervention; locus of control; PRIO project; recovery; self-rostering; shift work; working hours; worktime control

This article in PubMed: www.ncbi.nlm.nih.gov/pubmed/22648286 


\title{
Implementation of self-rostering (the PRI0 project): effects on working hours, recovery, and health
}

\author{
by Anne Helene Garde, PhD, ${ }^{1}$ Karen Albertsen, PhD, ${ }^{2,}$, Kirsten Nabe-Nielsen, PhD, ${ }^{2}$ Isabella Gomes \\ Carneiro, Phd, ${ }^{1}$ Jørgen Skotte, MSc Eng, ${ }^{1}$ Sofie Mandrup Hansen, MSc, ${ }^{1}$ Henrik Lund, Phd, ${ }^{4}$ Helge Hvid, \\ Phd, ${ }^{4}$ Åse Marie Hansen, $P h D^{1,2}$
}

\begin{abstract}
Garde AH, Albertsen K, Nabe-Nielsen K, Carneiro IG, Skotte J, Hansen SM, Lund H, Hvid H, Hansen ÅM. Implementation of self-rostering (the PRIO project): effects on working hours, recovery, and health. Scand J Work Environ Health. 2012;38(4):314-326. doi:10.5271/sjweh.3306
\end{abstract}

Objectives The aim of this study was to (i) investigate the consequences of self-rostering for working hours, recovery, and health, and (ii) elucidate the mechanisms through which recovery and health are affected.

Methods Twenty eight workplaces were allocated to either an intervention or reference group. Intervention A encompassed the possibility to specify preferences for starting time and length of shift down to 15 minutes intervals. Interventions B and C included the opportunity to choose between a number of predefined duties. Questionnaires $(\mathrm{N}=840)$ on recovery and health and objective workplace reports of working hours $(\mathrm{N}=718)$ were obtained at baseline and 12 months later. The interaction term between intervention and time was tested in mixed models and multinomial logistic regression models.

Results The odds ratio (OR) of having short [OR 4.8, $95 \%$ confidence interval $(95 \% \mathrm{CI}) 1.9-12.3]$ and long (OR 4.8, 95\% CI 2.9-8.0) shifts increased in intervention A. Somatic symptoms ( $\beta=-0.10,95 \%$ CI $-0.19-0.02)$ and mental distress $(\beta=-0.13,95 \% \mathrm{CI}-0.23--0.03)$ decreased, and sleep $(\beta=1.7,95 \% \mathrm{CI} 0.04-0.30)$ improved in intervention $\mathrm{B}$, and need for recovery was reduced in interventions $\mathrm{A}(\beta=-0.17,95 \% \mathrm{CI}-0.29--0.04)$ and $\mathrm{B}$ ( $\beta=$ $-0.17,95 \% \mathrm{CI}-0.27--0.07$ ). There were no effects on recovery and health in intervention $\mathrm{C}$, and overall, there were no detrimental effects on recovery or health. The benefits of the intervention were not related to changes in working hours and did not differ by gender, age, family type, degree of employment, or working hour arrangements.

Conclusions After implementation of self-rostering, employees changed shift length and timing but did not compromise most recommendations for acceptable shift work schedules. Positive consequences of self-rostering for recovery and health were observed, particularly in intervention B where worktime control increased but less extensively than intervention A. The effect could not be statistically explained by changes in actual working hours.

Key terms healthcare; intervention; locus of control; shift work; worktime control.

Shift work is required in many occupations, such as the healthcare sector. Hence it is crucial to provide knowledge on how to reduce the potentially negative effects of shift work on work-life balance, sleep, and health (1-3). The employee's ability to influence working hours (worktime control) has been associated with improved work-life balance (4-6), fewer subjective health complaints (7), less medically certified sickness absence (8), lower likelihood of worker disability pension (9), and reduced turn-over (10). Although other studies failed to find similar effects (11-13), Joyce et al (14) tentatively concluded in their Cochrane review that flexible working interventions that increase worker control and choice are likely to have a positive effect on health outcomes but also that further intervention studies are needed. Furthermore, evidence is lacking on mechanisms through which increased worktime control may affect social life and health.

One theoretical explanation is that it provides the individual employee with the possibility to adjust working

\footnotetext{
${ }^{1}$ National Research Centre for the Working Environment, Copenhagen, Denmark.

2 Department of Public Health, University of Copenhagen, Copenhagen, Denmark.

3 Team Working Life, Trekronergade 15, 2500 Valby, Denmark.

4 The Department of Environmental, Social and Spatial Change, Roskilde University, Universitetsvej 1, PO Box 260, 4000 Roskilde, Denmark.

Correspondence: Anne Helene Garde, Lersø Parkallé 105, 2100 København Ø, Denmark. [E-mail: ahg@nrcwe.dk]
} 
hours to individual needs and preferences, eg, personal resources, demands from their private life and need for restitution $(8,15)$. Gareis \& Barnett (16) found that high "schedule fit" (ie, that the working hours meet the employee's needs) was associated with lower psychological distress. Even when worktime control does not imply an opportunity to change the number of total hours worked, employees may use their influence to change the timing of their working hours according to their preferences. Such changes may be relevant for health and wellbeing, since a misfit between preferences and workplace reports of working hours is associated with an increased dissatisfaction with working hours (17).

Another theoretical assumption suggests that merely having the possibility to influence working hours reduces stress responses. According to this assumption, positive effects of worktime control on health and well-being stem from the stress-reducing effect of perceived influence over scheduling working hours, even if the actual working hours are not changed. This assumption is in accordance with theoretical constructs about the healthpromoting and stress-reducing effects of perceived individual control, eg, locus of control $(18,19)$ and self-efficacy (20).

Influence on working hours may be accomplished in many ways: eg, using a "paper and pen" method (4), via corporate-level organizational change with the purpose of altering the temporal structure of work (10), and through self-rostering, where employees are given the opportunity to plan their own work schedules on a running basis with IT software (5).

In spite of the empirical findings pointing at the positive effects of worktime control, concerns have been raised that the influence attained by employees may be used to choose working hours that do not favor health (21). Existing guidelines for the design of acceptable work schedules prescribe a limited number of consecutive workdays and duration of shifts (depending on the workload), and a limitation of weekend work $(22,23)$. If employees choose working hours that do not favor health, increased influence may be deleterious even if employees report more satisfaction with working hours and positive effects on social life.

Introduction of self-rostering may reach different groups of employees to a different degree. Although suffering most health consequences, workers who work only night have been found to be reluctant to take part in interventions introducing more worktime control (12). Further, elderly employees have been found to be less likely than younger employees to use the possibility of a time bank and a veto option (5). On the other hand, women and families with children may benefit more from the intervention due to many other obligations related to childcare. It has also been speculated that a part-time schedule may leave enough room for flexibility and therefore make (increased) worktime control less efficient compared to a full-time schedule (12). It is therefore relevant to provide knowledge on the effect of the intervention on groups differentiated by, for example, age, gender, family type, degree of employment (full-time/part time), and working hour arrangement (day, evening, night or irregular shifts with or without work at night).

The aim of the present study was to investigate the consequences of the implementation of self-rostering on working hours, recovery, and health, and shed light on the mechanisms through which self-rostering may affect recovery and health.

Hypothesis 1 was that implementation of self-rostering is followed by: (a) changes in workplace reports of working hours: since this is the first study to include objective workplace reports of working hours, we do not have a priori assumptions about how the working hours may change; (b) increased self-reports of influence on and satisfaction with working hours; and (c) improved health in terms of less need for recovery, better sleep, fewer somatic symptoms, and less mental distress.

Hypothesis 2 was in two parts: (a) changes in working hours mediate the effects of the intervention on need for recovery, sleep, sick leave, somatic symptoms, and mental distress; and (b) the effect of the intervention on influence over and satisfaction with working hours, recovery and health differs between groups of individuals defined by age, gender, family type, full-time/part-time employment and shifts (day, evening, night, and rotating shifts).

To our knowledge, this is the largest intervention study on self-rostering among shift workers to date and the first study to include changes in objective workplace reports of working hours and to combine them with self-reports.

\section{Methods}

\section{Study design and population}

The present intervention study was a longitudinal, quasiexperimental study. Workplaces planning to implement self-rostering were recruited through public advertising, meetings, and personal contacts. All activities related to the interventions were planned, executed, and financed by the companies. Data were collected at baseline and 12 months later (follow-up), when all interventions had been implemented for at least 9 months. The time of initiation of the interventions differed between the workplaces, and they were enrolled in the study when ready. The baseline survey took place between October 2008-2009.

In total, nine companies covering 28 workplaces were included. They were allocated to an intervention $(\mathrm{N}=14$ 
workplaces) or a reference group ( $\mathrm{N}=14$ workplaces) in clusters. Allocation to the intervention or reference groups was decided by the company or workplace (ie, non-randomized). Objective workplace reports of working hours for all personnel were obtained from 25 of the 28 included workplaces at both baseline $(\mathrm{N}=718)$ and follow-up ( $\mathrm{N}=849)$ because three workplaces failed to deliver the data. At the time of the surveys, all personnel at the workplaces were invited to fill in a questionnaire. Response rates were $78.9 \%(\mathrm{~N}=840)$ at baseline and $73.1 \%$ at follow-up $(\mathrm{N}=791)$. At 13 of the 14 intervention workplaces, management completed workplace questionnaires on the context of implementation.

The study complied with the Act on Processing of Personal Data (Act number 429 of 31 May 2000), which implements the European Union Directive 95/46/EC on the protection of individuals. The Danish Data Protection Agency approved the data usage (reference number: 2008-54-0458).

\section{The intervention}

The planned intervention was to introduce and implement self-rostering by use of commercially available IT software chosen by the company. To fulfill the inclusion criteria, the IT software had to allow the employer to define the need for man-power on an ongoing basis and for employees to choose their work schedule (ie, what days they wanted to work or did not want to work). In addition, the intervention could include a choice of shift length, starting and ending times, as well as the possibility to transfer hours from one period to another (a time bank). A new work schedule based on the preferences of the employees and the staff needs of the workplace was generated. Some intervention workplaces included a puzzle phase, where the employees were invited to solve discrepancies between preferences and the staff needs by voluntarily altering their indicated preferences. Final adjustments were made by the managers, and all schedules were published with four weeks notice in agreement with the unions.

The intervention workplaces used three different IT softwares. They resembled each other and had more or less the same possibilities. Even so, there were differences in how they were introduced, which affected the implementation of the interventions. Therefore, we constructed three groups of interventions based on the choice of IT software.

Intervention $A$. This intervention was implemented among all caregivers at six workplaces, mainly psychiatric and somatic hospital care settings. All had a need for 24/7 staffing. The main aims for introducing selfrostering were to increase the employees' satisfaction with working hours and well-being and thereby ensure the possibilities for recruitment and retention. Before the intervention, working hours were planned for 4-8 weeks at a time and announced with $\geq 4$ weeks notice. As in most healthcare settings in Denmark, the employees' preferences were considered if possible. The preferences were written down on paper, which put a natural limit to the number of preferences employees could enter.

According to the workplace questionnaire, the implementation process involved both the work council and the union representatives at 4 of 5 workplaces, respectively. The employees were involved in the implementation process to a (very) high degree at 3 of 5 workplaces. The workplaces experienced either a little (1 of 5 workplaces), some ( 3 of 5 workplaces), or a high degree (1 of 5 workplaces) of technical problems with the IT software implementation, and the employees at all workplaces received training in the use of the software as part of the implementation process.

After the intervention was implemented, the employees could enter their work schedule preferences at the workplace or from home via the internet. New work schedules were made every 1-5 weeks. Traditionally employees have organized their private life around their working hours. In intervention A, employees were encouraged to reconsider their usual habits and attitudes and instead organize their working hours around their private life. The intervention included a time bank, where the employees were allowed to have -100-200 hours at the end of a planning period. There was a "puzzle phase", and the possibility to specify wishes separately for starting time and length of shift down to 15 minutes intervals. Workplaces were free to set their own guidelines concerning what work schedules were allowed. The minimum limit between two duties ranged from 8-11 hours and the allowed number of consecutive work days ranged from 6-12 days depending on workplace. The shortest duties allowed were 1-6 hours, whereas all workplaces had a limit of 12 hours as the longest duty. According to the workplace questionnaires, 75-90 \% of the employees' wishes were fulfilled after the implementation of self-rostering.

Intervention $B$. The participants in intervention B consisted of caregivers from seven workplaces including psychiatric care settings and intensive and somatic care units in hospitals. All had a need for 24/7 staffing. A few employees did not participate in the intervention (eg, due to social or health problems). The main aim of introducing self-rostering was to increase the employees' well-being and satisfaction with working hours, thereby enhancing recruitment and retention. Before the intervention, working hours were planned for 4-8 weeks at a time and announced with $\geq 4$ weeks notice. The employees' preferences were written down on paper and considered where possible. 
According to the workplace questionnaires, the implementation process involved the work council at 4 of 7 workplaces and the union representatives at 5 of 7 workplaces. The employees were involved in the implementation process to a (very) high degree at all the workplaces. The workplaces experienced either no or a little (4 of 7 workplaces), or a (very) high degree ( 3 of 7 workplaces) of technical problems with implementation of the IT software, and the employees at all workplaces received training in the use of the software as part of the implementation process.

After the intervention was implemented, the employees could enter their work schedule preferences at the workplace or from home via the internet. New individual work schedules were made every $4-12$ weeks. Employees in intervention B could choose what days they wanted to work and not to work, and could choose between a limited number of predefined types of duties. This intervention did not include a time bank or a puzzle phase. Workplaces were free to set their own guidelines concerning what work schedules were allowed. The minimum limit between two duties ranged from 8-11 hours and the allowed number of consecutive work days ranged from 6-8 days depending on the workplace. The longest allowed duty was 12-13 hours depending on the workplace, whereas all workplaces had a limit of 5 hours as the minimum duty. Workplace questionnaires indicated that $75-80 \%$ of the employees' preferences were fulfilled after the implementation.

Intervention C. This intervention was implemented in a financial sector call center. The opening hours were from 08:00-20:00 Monday-Friday and 08:00-16:00 on weekends. A few employees did not participate in the intervention due to either social or health problems. The main aim of intervention $C$ was to optimize the use of staffing resources in relation to the needs of the company, and secondly to improve the workers' satisfaction with the working hours. Before the intervention, all employees had a stable 4-week roster with good possibilities to swap duties.

According to the workplace questionnaire, the work council was involved to a low degree, union representatives to a high degree, and employees to some degree in the implementation process of the self-rostering IT software. The call center had experienced some technical problems with implementation of the IT software, and the employees had received training in the use of the software as part of the implementation process.

After the intervention was implemented, the employees had the possibility to enter their preferences for specific shifts during the work day, but not from home via the internet. New work schedules were made every 12 weeks. Intervention $\mathrm{C}$ included a time bank and a puzzle phase. Furthermore, the employer introduced a buffer of 45 minutes around the preferred start and end time in order to allow for flexibility in the schedule planning (ie, if an employee chose to start at 09.00 hours, the scheduled starting time could be between 08.15 and 09.45 hours). There was a minimum limit of 11 hours between two preferred duties and a limit of maximum 6 workdays in a row. The longest allowed duty was 10 hours and the shortest was 4 hours. It was not reported how many of the employees' preferences were fulfilled.

\section{Reference group}

The reference group comprised psychiatric, intensive, and somatic hospital wards and a handicap home. All had a need for $24 / 7$ staffing. Workplaces in the reference group reported in telephone interviews that they refrained from engaging in a working hour intervention during the study period.

\section{Background/effect modifiers}

Age and gender were assessed from personal ID numbers, which included this information. Age was divided into four categories: $\leq 29$ years; $30-39$ years; $40-49$ years and $\geq 50$ years. Family type was assessed from self-reports and categorized into: (i) single without children; (ii) single with children; (iii) couple without children; and (iv) couple with children.

\section{Effect measures}

In questionnaires we asked: "To what extent do you experience having influence on the arrangement of your working hours?" and "Are you satisfied with your working hours?". The responses (originally 5 response categories) were trichotomized into: to a (very) small extent, somewhat, and to a (very) large extent. Furthermore, we asked: "Do you have the possibility to plan (i) how long your duty is? (ii) what time of the day to work? and (iii) what days to work?". The responses were trichotomized into: hardly ever/seldom, sometimes, and often/always. We also asked: "Have you within the last 12 months considered changing job in order to change your working hours?". Response categories were yes and no.

Need for recovery was assessed using 9 items, eg, "difficulties to relax after a workday" and "cannot concentrate after work" $(24,25)$. The five response categories were: $1=$ never, $2=$ rarely, $3=$ some of the time, $4=$ most of the time, and $5=$ always. A need for recovery index was composed as the mean of all items (Cronbach's alpha $=0.89$ ). A revised version of the Karolinska Sleep Questionnaire was used to evaluate sleep (26). Response categories were $0=$ always, $1=$ most of the time, $2=$ sometimes, $3=$ rarely, $4=$ never. An index of disturbed sleep (DSI) was composed as the mean of 4 
items (difficulties falling asleep, premature awakening, repeated awakening, and disturbed/restless sleep). The awakening index (AWI) was composed as the mean of three items (difficulties waking up, non-refreshing sleep, and exhausted on waking). In both cases, a higher score represented better sleep. Cronbach's alphas were 0.84 for DSI and 0.77 for AWI.

A reduced form of the Symptom Checklist-90 (SCL90) (39) was used to assess mental distress and somatic symptoms over the past four weeks. The present version encompassed 12 somatic symptoms: headache, faintness or dizziness, pains in heart or chest, heart pounding or racing, pains in lower back, nausea or upset stomach, muscles soreness, poor appetite, loose stools/costiveness, gas, feeling weak in part of body, and heavy feeling in arms or legs. Respondents were asked to grade the degree of each complaint on a 5-point scale $(1=$ not at all, $2=$ a little bit, $3=$ moderately, $4=$ quite a bit, $5=$ extremely). An index of somatic symptoms was composed as the mean of all items (Cronbach's alpha=0.83). Eight symptoms of mental distress were included: feeling blue, feeling worthless, feeling guilty, no interest in daily life, difficulties in relaxing, feeling easily annoyed or irritated, feeling tense or keyed up, or feeling stressed. Response categories were: $1=$ never, $2=a$ little of the time, $3=$ some of the time, $4=$ most of the time, $5=$ all the time. An index of mental distress was composed as the mean of all items (Cronbach's alpha $=0.90$ ).

For all participants, workplace reports of objective working hours were collected for a 4-week period at baseline and follow-up. Dates, starting and ending times of duties, and days off were imported into a database. If the participant was registered as absent due to illness on a planned workday, the planned working hours were included to avoid that sick leave was mistaken for a day off. Assessed working hour characteristics included: working hours per week, length of shift, and variation in shift length and timing defined as the sum of the standard deviation of length of shift and the standard deviation of midpoint time of shift (27). Furthermore, we assessed the number of short shifts (ie, shifts lasting $\leq 4$ hours) in 3 categories $(0,1-2$, and $\geq 3$ shifts), and long and very long shifts (ie, shifts lasting $\geq 9$ and $\geq 12$ hours, respectively) in 4 categories $(0,1-3,4-7$, and $\geq 8$ shifts), and number of day, evening, and night shifts. Day shifts were defined as shifts starting after 04:00 and ending before 19:00 hours ( 4 categories: $0,1-7,8-14$, and $\geq 15$ shifts), evening shifts as those ending between 19:00-01:00 hours ( 4 categories: $0,1-3,4-7$, and $\geq 8$ shifts), and night shifts as those starting between 19:00-04:00 hours and ending after 01:00 hours (5 categories: $0,1-3,4-7,8-14$, and $\geq 15$ shifts). Affected weekends was assessed as the number of Saturday plus Sunday shifts (range: 0-8 days; 3 categories: 0 , $1-4$, and $\geq 5$ shifts on Saturday and/or Sunday), and number of work weekends as weekends spent working both
Saturday and Sunday (range: $0-4$ weekends; 3 categories: 0,1 , and $\geq 2$ weekends with work). We also assessed the number of sequences with $\geq 6$ consecutive workdays ( 2 categories: 0 and $\geq 1$ sequences with $\geq 6$ consecutive days), and number of sequences with $\geq 4$ consecutive nights shifts ( 3 categories: 0,1 , and $\geq 2$ sequences with $\geq 4$ consecutive nights), number of single days off ( 3 categories: $0,1-9$, and $\geq 10$ single days off), number of sequences with $\geq 3$ consecutive days off ( 3 categories: $0,1-3$, and $\geq 4$ sequences with $\geq 3$ consecutive days off), number of quick returns ( $<9$ hours between two duties; 2 categories: 0 and $\geq 1$ ), and number of early morning shifts (ie, shifts starting before 06:00). All categorized values are per 28 days.

\section{Statistical analysis}

Data analyses were performed using SAS statistical software version 9.2. (SAS Institute Inc, Cary, NC, USA). Differences in age between the three interventions and the reference group at baseline were tested through analysis of variance (ANOVA). For all other variables Kruskal-Wallis test via a non-parametric NPAR1WAY procedure was performed.

Using generalized mixed models (PROC MIXED) with a repeated statement (compound symmetry) to account for within-person associations, we statistically analyzed whether the change from baseline to followup in the three intervention groups differed from the change in the reference group with respect to (i) workplace reports of the continuous working hour variables (weekly working hours, shift length and variation in shift length and timing), and (ii) need for recovery, sleep, somatic symptoms, and mental distress. Changes in all ordinal working hour variables and self-reports of influence on and satisfaction with working hours were made by using multinomial logistic regression (PROC GENMOD) with the clogit link as this generalizes logistic regression by allowing more than two discrete outcomes. Ordinal variables were analyzed through the generalized estimating equations (GEE) method to account for the within-person associations. Since only workplace reports of working hours were needed for our first hypothesis (1a), the analysis included employees, who had not answered the questionnaires. Since only information from questionnaires was needed for hypotheses $1 \mathrm{~b}$ and $\mathrm{c}$, the analysis included employees, where no workplace reports of working hours were obtained. The models included time (2 levels: baseline and follow-up), intervention (4 levels: interventions $\mathrm{A}, \mathrm{B}$, and $\mathrm{C}$ and reference) and the interaction term time $\times$ intervention. The interaction term was made with reference to time and intervention and expressed as the extent to which the outcome at follow-up in interventions $\mathrm{A}, \mathrm{B}$, and $\mathrm{C}$ differed significantly from what would have been expected from (i) the baseline differ- 
ence between each of the intervention groups and the reference group (intervention effect) and from (ii) the difference between the baseline and follow-up level in the reference group (time effect). The results are presented as overall $\mathrm{P}$-values (intervention, time, and time $\times$ intervention) and odds ratios (OR) or $\beta$-coefficient estimating the time $\times$ intervention effect.

In the analyses for hypotheses $2 a$ and $2 b$, the intervention groups were combined in order to gain sufficient power and because we were looking for an overall effect across interventions. To test if changes in working hours mediated the effects of the intervention (hypothesis 2a), new models for need for recovery, sleep, somatic symptoms, and mental distress were made by expanding the initial models with dichotomized variables of working hours (number of short shifts, long shifts, weekend work, $>6$ consecutive workdays, $>4$ consecutive nights shifts, number of single days off, $>3$ consecutive days off, and quick returns) one at a time. The dataset included only those employees for whom we had obtained both questionnaire and working hour data. The reference group was excluded, because there were no changes in working hours in this group. P-values of the working hour variable and intervention as well as the effect estimate of intervention were considered.

To test if the effect of the intervention differed between groups (hypothesis 2b), new models for satisfaction with working hours, need for recovery, sleep, somatic symptoms, and mental distress were made by expanding the above models with a 3 -factor interaction term (intervention $\times$ time $\times$ gender/age/family type/ full-time/work schedule) and all 2-way interaction and main terms. P-values for the 3-way interaction terms were considered.

All models were adjusted for age and gender. Due to the large number of working hours variables $(\mathrm{N}=17)$, we applied Bonferroni correction, and a P-value of 0.012 was considered significant when working hours were included (hypotheses 1a and 2a). Self-rostering is implemented at workplace level and new employees are also exposed to the intervention. Therefore we perform statistical analysis on all data collected at baseline and/or follow-up.

\section{Results}

Distributions of gender, age, living with a partner, children at home, full-time work, work schedule, and influence on working hours at baseline are given in table 1 . The lowest degree of full-time employment was observed among employees in intervention A. We observed the highest number of employees with irregular working hours among employees in intervention B, and the lowest percentage of women and the highest number of daytime workers among employees in intervention C. No significant differences were observed between the intervention groups with respect to the

Table 1. Group characteristics at baseline. Distributions of gender, age, living with a partner, children at home, full-time work, work schedule, and influence on working hours at baseline.

\begin{tabular}{|c|c|c|c|c|c|c|c|c|c|c|c|c|c|c|c|c|}
\hline & \multicolumn{12}{|c|}{ Intervention } & \multirow{2}{*}{\multicolumn{3}{|c|}{ Reference }} & \multirow[t]{3}{*}{$\mathrm{P}$-value ${ }^{\mathrm{a}}$} \\
\hline & \multicolumn{3}{|c|}{ Total } & \multicolumn{3}{|c|}{ A } & \multicolumn{3}{|c|}{$\mathrm{B}$} & \multicolumn{3}{|c|}{$\mathrm{C}$} & & & & \\
\hline & Mean & $\mathrm{N}$ & $\%$ & Mean & $\mathrm{N}$ & $\%$ & Mean & $\mathrm{N}$ & $\%$ & Mean & $\mathrm{N}$ & $\%$ & Mean & N & $\%$ & \\
\hline Companies & & 8 & & & 3 & & & 4 & & & 1 & & & 6 & & \\
\hline Workplaces & & 14 & & & 6 & & & 7 & & & 1 & & & 14 & & \\
\hline Workplaces per company & & $0-3$ & & & $1-3$ & & & $1-3$ & & & 1 & & & $0-7$ & & \\
\hline Employees & & 493 & & & 135 & & & 259 & & & 99 & & & 347 & & \\
\hline Women & & & 92 & & & 91 & & & 96 & & & 82 & & & 90 & $<0.0001$ \\
\hline Age (years) & 42 & & & 44 & & & 41 & & & 43 & & & 46 & & & $<0.0001$ \\
\hline Living with partner & & & 78 & & & 72 & & & 78 & & & 89 & & & 79 & 0.022 \\
\hline Children at home & & & 58 & & & 62 & & & 57 & & & 54 & & & 54 & 0.357 \\
\hline Full-time & & & 57 & & & 36 & & & 64 & & & 67 & & & 51 & 0.078 \\
\hline Work schedule & & & & & & & & & & & & & & & & $<0.0001$ \\
\hline Day & & & 46 & & & 45 & & & 27 & & & 94 & & & 50 & \\
\hline Evening & & & 6 & & & 10 & & & 7 & & & 0 & & & 13 & \\
\hline Night & & & 5 & & & 12 & & & 3 & & & 0 & & & 9 & \\
\hline Irregular shifts & & & 43 & & & 33 & & & 63 & & & 6 & & & 29 & \\
\hline Influence on working hours & & & & & & & & & & & & & & & & 0.334 \\
\hline Very little degree & & & 4 & & & 8 & & & 2 & & & 2 & & & 7 & \\
\hline Little degree & & & 13 & & & 20 & & & 11 & & & 11 & & & 15 & \\
\hline Some & & & 40 & & & 32 & & & 47 & & & 34 & & & 38 & \\
\hline High degree & & & 28 & & & 23 & & & 28 & & & 34 & & & 23 & \\
\hline Very high degree & & & 15 & & & 17 & & & 12 & & & 19 & & & 16 & \\
\hline
\end{tabular}

a For difference between 4 groups (interventions A, B, C and reference groups). Analysis of variance (ANOVA) was used for age. Kruskal-Wallis test was used for all other variables. 
number of participants living with children and degree of influence on working hours. All in all, intervention groups A and B are comparable to the reference group at baseline. Intervention group $\mathrm{C}$ differs from the other groups by being a non-healthcare-related call center and not having work at night. Outcome data are presented as distributions or means with standard deviations (SD) in table 2 for workplace reports of objective working hours and in tables $3 \mathrm{a}$ and $3 \mathrm{~b}$ for self-reports.

\section{Hypothesis 1a}

Table 4 shows the changes in working hour arrangement after introduction of self-rostering in interventions $\mathrm{A}$ and $\mathrm{B}$ (intervention $\mathrm{C}$ is not included due to lack of data). Intervention A showed increased odds of having shifts lasting $\leq 4$ hours (OR 4.8, 95\% CI 1.9-12.3) and having duties lasting $\geq 9$ hours (OR 4.8, 95\% CI 2.9-8.0) after adjustment for baseline level, group level, age, and gender. The mean shift length was increased ( $\beta$ 0.69, 95\% CI $0.21-1.17$ ). No statistically significant changes in working hours in intervention B were observed.

\section{Hypothesis $1 b$}

Self-reported influence on working hours increased significantly in intervention A (OR 5.9, 95\% CI 3.2-11.0) and intervention B (OR 3.3, 95\% CI 2.1-5.3), but not in intervention $\mathrm{C}$, after adjustment for baseline level, group level, age, and gender (table 5). Influence on working hours in terms of the possibility to prefer different lengths of duty (OR 7.1, 95\% CI 4.1-12.1), time of day (OR 6.4, 95\% CI 3.7-11.2) and what day to work (OR 7.0, 95\% CI 3.7-12.9) increased in intervention A compared to the reference group. In intervention $\mathrm{B}$, the possibility to choose what day to work increased (OR $2.5,95 \% \mathrm{CI}$ 1.6-3.8), and, in intervention $C$, the possibility to choose length of duty increased (OR 2.2, 95\% CI 1.3-3.7). Satisfaction with working hours increased in intervention $\mathrm{A}$ (OR 2.5, 95\% CI 1.4-4.4) and decreased in intervention C (OR 0.36, 95\% CI 0.21-0.63), whereas there was no statistically significant change in intervention B.

\section{Hypothesis 1c}

Need for recovery decreased after implementation of self-rostering in intervention $A(\beta=-0.17,95 \%$ CI -0.29 $-0.04)$ and intervention $\mathrm{B}(\beta=-0.17,95 \% \mathrm{CI}-0.27--0.07)$ compared to the reference group, when adjusted for baseline level, group level, age, and gender (table 5). Employees in intervention B (but not A or C) experienced fewer somatic symptoms ( $\beta=-0.1095 \%$ CI $-0.19-0.02)$, less mental distress $(\beta=-0.13,95 \%$ CI $-0.23--0.03)$, and better sleep in terms of higher DSI $(\beta=0.1795 \%$ CI 0.04-0.30) after implementation of self-rostering.
No statistically significant changes in intervention $\mathrm{C}$ were observed, and there were no statistically significant observations of deterioration of recovery, sleep, or health.

\section{Hypothesis 2a}

Inclusion of working hour variables did not change the estimate or the P-value for change in need for recovery, sleep, somatic symptoms, and mental distress over time substantially (data not shown, but available from the first author).

\section{Hypothesis $2 b$}

The 3-way interaction term timexintervention $\times$ working hour arrangement reached statistical significance for DSI $(\mathrm{P}=0.047)$. All other effects of the interventions on satisfaction with working hours, need for recovery, DSI, AWI, somatic symptoms, and mental distress did not differ between age-groups, gender, family type, degree of employment, or working hour arrangement (data not shown, but available from the first author).

\section{Discussion}

The aims of the present study were to (i) explore the consequences of implementation of self-rostering on working hours, recovery, sleep, and health and (ii) shed light on the mechanisms through which self-rostering may affect recovery and health. Our main results showed that implementation of self-rostering was associated with changes in working hours in intervention $\mathrm{A}$, improved health in intervention $B$, and less need for recovery in both interventions A and B. Importantly, we found no detrimental effects on the need for recovery, sleep, or health. The effects of implementation of self-rostering could not be statistically explained by changes in working hours and did not differ by gender, age, family type, degree of employment, or working-hour arrangement.

Self-rostering was implemented at all workplaces in the intervention group and not in the reference group. From questionnaires, it was confirmed that the intervention reached the employees: at follow-up, they had increased OR for having the possibility to choose length of duty, time of day, and what day to work. Thus it may be assumed that the intervention was implemented as intended and reached the employees, which is the first necessary step in intervention research (28). The highest OR were observed for intervention A, which is in accordance with differences in the implementation of selfrostering. Intervention A included a time bank and the possibility to choose separately starting time and length of shift down to 15 minutes intervals. In contrast, inter- 
Table 2. Workplace reports of working hour data. [SD=standard deviation]

\begin{tabular}{|c|c|c|c|c|c|c|c|c|c|c|c|c|c|c|c|c|c|c|}
\hline & \multicolumn{6}{|c|}{ Intervention A } & \multicolumn{6}{|c|}{ Intervention B } & \multicolumn{6}{|c|}{ Intervention C } \\
\hline & \multicolumn{3}{|c|}{ Baseline } & \multicolumn{3}{|c|}{ Follow-up } & \multicolumn{3}{|c|}{ Baseline } & \multicolumn{3}{|c|}{ Follow-up } & \multicolumn{3}{|c|}{ Baseline } & \multicolumn{3}{|c|}{ Follow-up } \\
\hline & $\%$ & Mean & SD & $\%$ & Mean & SD & $\%$ & Mean & SD & $\%$ & Mean & SD & $\%$ & Mean & SD & $\%$ & Mean & SD \\
\hline Hours per week & & 30.8 & 0.6 & & 30.5 & 0.7 & & 26.8 & 0.5 & & 27.6 & 0.6 & & 29.3 & 0.5 & & 28.9 & 0.4 \\
\hline Variability (work hours) & & 3.4 & 0.2 & & 4.4 & 0.2 & & 4.5 & 0.2 & & 4.6 & 0.1 & & 3.3 & 0.1 & & 3.6 & 0.1 \\
\hline Shift length (hours) & & 7.9 & 0.0 & & 8.0 & 0.1 & & 8.2 & 0.4 & & 8.3 & 0.4 & & 7.9 & 0.1 & & 8.1 & 0.0 \\
\hline Number of day shifts & & & & & & & & & & & & & & & & & & \\
\hline 0 & 14 & & & 11 & & & 11 & & & 9 & & & 12 & & & 11 & & \\
\hline $1-7$ & 20 & & & 18 & & & 42 & & & 36 & & & 24 & & & 21 & & \\
\hline $8-14$ & 41 & & & 53 & & & 40 & & & 50 & & & 40 & & & 48 & & \\
\hline$\geq 15$ & 25 & & & 18 & & & 7 & 7 & & 5 & & & 24 & & & 20 & & \\
\hline $\begin{array}{l}\text { Number of evening } \\
\text { shifts }\end{array}$ & & & & & & & & & & & & & & & & & & \\
\hline 0 & 38 & & & 28 & & & 30 & & & 34 & & & 39 & & & 38 & & \\
\hline $1-3$ & 22 & & & 24 & & & 27 & & & 17 & & & 26 & & & 20 & & \\
\hline $4-7$ & 24 & & & 27 & & & 30 & & & 26 & & & 16 & & & 25 & & \\
\hline$\geq 8$ & 16 & & & 21 & & & 13 & & & 23 & & & 19 & & & 17 & & \\
\hline Number of night shifts & & & & & & & & & & & & & & & & & & \\
\hline 0 & 61 & & & 63 & & & 53 & & & 56 & & & 68 & & & 68 & & \\
\hline $1-3$ & 17 & & & 13 & & & 19 & & & 18 & & & 13 & & & 14 & & \\
\hline $4-7$ & 8 & & & 10 & & & 20 & & & 17 & & & 7 & & & 8 & 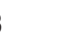 & \\
\hline $8-14$ & 10 & & & 9 & & & 8 & 3 & & 8 & & & 10 & & & 8 & 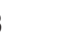 & \\
\hline$\geq 15$ & 34 & & & 5 & & & 0 & 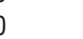 & & 1 & & & 2 & & & 2 & ? & \\
\hline Short shifts ( $\leq 4$ hours) & & & & & & & & & & & & & & & & & & \\
\hline 0 & 92 & & & 73 & & & 93 & & & 95 & & & 93 & & & 93 & & \\
\hline $1-2$ & 8 & & & 21 & & & 6 & 6 & & 4 & & & 6 & & & 6 & 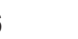 & \\
\hline$\geq 3$ & 0 & & & 6 & & & 1 & 1 & & 1 & & & 1 & & & 1 & & \\
\hline Long shifts ( $\geq 9$ hours) & & & & & & & & & & & & & & & & & & \\
\hline 0 & 61 & & & 30 & & & 52 & & & 45 & & & 58 & & & 58 & & \\
\hline $1-3$ & 35 & & & 46 & & & 43 & & & 44 & & & 36 & & & 37 & & \\
\hline $4-7$ & 4 & & & 22 & & & 5 & 5 & & 10 & & & 6 & & & 4 & 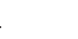 & \\
\hline$\geq 8$ & 0 & & & 2 & & & 0 & 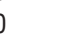 & & 1 & & & 0 & & & 0 & ) & \\
\hline $\begin{array}{l}\text { Very long shifts } \\
\text { ( } \geq 12 \text { hours) }\end{array}$ & & & & & & & & & & & & & & & & & & \\
\hline 0 & 78 & & & 71 & & & 59 & & & 51 & & & 87 & & & 80 & & \\
\hline $1-3$ & 20 & & & 25 & & & 38 & & & 41 & & & 13 & & & 19 & & \\
\hline$\geq 4$ & 2 & & & 4 & & & 3 & 3 & & 8 & & & 0 & & & 1 & & \\
\hline Single workdays & & & & & & & & & & & & & & & & & & \\
\hline 0 & 32 & & & 29 & & & 26 & & & 29 & & & 31 & & & 28 & & \\
\hline $1-3$ & 64 & & & 60 & & & 69 & & & 66 & & & 61 & & & 65 & & \\
\hline$\geq 4$ & 4 & & & 11 & & & 5 & 5 & & 5 & & & 8 & & & 7 & 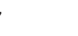 & \\
\hline $\begin{array}{l}\geq 6 \text { consecutive days } \\
\text { (sequences) }\end{array}$ & & & & & & & & & & & & & & & & & & \\
\hline 0 & 85 & & & 87 & & & 95 & & & 92 & & & 94 & & & 94 & & \\
\hline$\geq 2$ & 15 & & & 13 & & & 5 & 5 & & 8 & & & 6 & & & 6 & 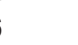 & \\
\hline $\begin{array}{l}\text { Both Saturday and } \\
\text { Sunday (weekend) }\end{array}$ & & & & & & & & & & & & & & & & & & \\
\hline 0 & 16 & & & 14 & & & 13 & & & 15 & & & 21 & & & 16 & & \\
\hline 1 & 28 & & & 21 & & & 49 & & & 40 & & & 23 & & & 31 & & \\
\hline$\geq 2$ & 56 & & & 65 & & & 38 & & & 45 & & & 56 & & & 53 & & \\
\hline $\begin{array}{l}\text { Saturday or Sunday } \\
\text { shifts }\end{array}$ & & & & & & & & & & & & & & & & & & \\
\hline 0 & 16 & & & 14 & & & 13 & & & 15 & & & 21 & & & 16 & & \\
\hline $1-4$ & 73 & & & 65 & & & 81 & & & 75 & & & 72 & & & 78 & & \\
\hline$\geq 5$ & 11 & & & 21 & & & 6 & 6 & & 10 & & & 7 & & & 6 & ; & \\
\hline Single day off & & & & & & & & & & & & & & & & & & \\
\hline 0 & 1 & & & 3 & & & 4 & 4 & & 6 & & & 2 & & & 2 & ? & \\
\hline $1-9$ & 34 & & & 37 & & & 62 & & & 52 & & & 45 & & & 48 & & \\
\hline$\geq 10$ & 65 & & & 60 & & & 34 & & & 42 & & & 53 & & & 50 & & \\
\hline $\begin{array}{l}>3 \text { consecutive days } \\
\text { off (sequences) }\end{array}$ & & & & & & & & & & & & & & & & & & \\
\hline 0 & 18 & & & 24 & & & 18 & & & 18 & & & 27 & & & 60 & & \\
\hline $1-3$ & 43 & & & 47 & & & 43 & & & 35 & & & 39 & & & 30 & & \\
\hline$\geq 4$ & 39 & & & 29 & & & 39 & & & 47 & & & 34 & & & 10 & & \\
\hline $\begin{array}{l}>4 \text { consecutive night } \\
\text { shifts (sequences) }\end{array}$ & & & & & & & & & & & & & & & & & & \\
\hline 0 & 90 & & & 89 & & & 96 & & & 95 & & & 92 & & & 92 & & \\
\hline 1 & 7 & & & 7 & & & 4 & 4 & & 4 & & & 3 & & & 4 & 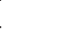 & \\
\hline$\geq 2$ & 23 & & & 4 & & & 0 & 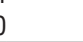 & & 1 & & & 5 & & & 4 & 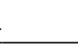 & \\
\hline
\end{tabular}


Table 3a. Self-reports of influence on working hours.

\begin{tabular}{|c|c|c|c|c|c|c|c|c|}
\hline & \multicolumn{2}{|c|}{ Intervention A } & \multicolumn{2}{|c|}{ Intervention B } & \multicolumn{2}{|c|}{ Intervention C } & \multicolumn{2}{|c|}{ Reference } \\
\hline & $\begin{array}{l}\text { Baseline } \\
(\mathrm{N}=127)\end{array}$ & $\begin{array}{c}\text { Follow-up } \\
(N=129)\end{array}$ & $\begin{array}{l}\text { Baseline } \\
(\mathrm{N}=246)\end{array}$ & $\begin{array}{c}\text { Follow-up } \\
(\mathrm{N}=193)\end{array}$ & $\begin{array}{c}\text { Baseline } \\
(\mathrm{N}=95)\end{array}$ & $\begin{array}{l}\text { Follow-up } \\
(\mathrm{N}=86)\end{array}$ & $\begin{array}{l}\text { Baseline } \\
(\mathrm{N}=336)\end{array}$ & $\begin{array}{c}\text { Follow-up } \\
(\mathrm{N}=325)\end{array}$ \\
\hline & $\%$ & $\%$ & $\%$ & $\%$ & $\%$ & $\%$ & $\%$ & $\%$ \\
\hline \multicolumn{9}{|l|}{ Influence on working hours } \\
\hline To a (very) small extent & 28 & 6 & 13 & 5 & 13 & 10 & 22 & 23 \\
\hline Somewhat & 32 & 24 & 47 & 29 & 34 & 44 & 38 & 34 \\
\hline To a (very) large extent & 40 & 70 & 40 & 66 & 53 & 45 & 39 & 43 \\
\hline \multicolumn{9}{|c|}{ Possibility to request length of duty } \\
\hline Hardly ever/sometimes & 66 & 20 & 59 & 56 & 29 & 13 & 67 & 68 \\
\hline Sometimes & 9 & 20 & 20 & 15 & 35 & 31 & 17 & 16 \\
\hline Often/always & 24 & 61 & 21 & 29 & 36 & 57 & 16 & 16 \\
\hline \multicolumn{9}{|c|}{ Possibility to plan what time of day } \\
\hline Hardly ever/sometimes & 59 & 19 & 52 & 44 & 35 & 20 & 63 & 59 \\
\hline Sometimes & 19 & 13 & 24 & 20 & 29 & 25 & 19 & 22 \\
\hline Often/always & 22 & 68 & 23 & 36 & 36 & 55 & 17 & 19 \\
\hline \multicolumn{9}{|c|}{ Possibility to plan what day to work } \\
\hline Hardly ever/sometimes & 39 & 7 & 18 & 7 & 38 & 15 & 44 & 36 \\
\hline Sometimes & 24 & 10 & 34 & 15 & 28 & 30 & 28 & 28 \\
\hline Often/always & 36 & 83 & 47 & 78 & 34 & 55 & 28 & 36 \\
\hline \multicolumn{9}{|c|}{ Satisfaction with working hours } \\
\hline Toa (very) small extent & 6 & 5 & 5 & 2 & 3 & 8 & 3 & 4 \\
\hline Somewhat & 45 & 20 & 41 & 32 & 29 & 42 & 36 & 30 \\
\hline To a (very) large extent & 49 & 76 & 54 & 66 & 67 & 50 & 61 & 66 \\
\hline \multicolumn{9}{|l|}{ Consider changing job } \\
\hline Yes & 31 & 23 & 39 & 26 & 16 & 30 & 32 & 28 \\
\hline
\end{tabular}

Table $\mathbf{3 b}$. Self-reports of need for recovery, sleep, and health. [SD=standard deviation]

\begin{tabular}{|c|c|c|c|c|c|c|c|c|c|c|c|c|c|c|c|c|}
\hline & \multicolumn{4}{|c|}{ Intervention A } & \multicolumn{4}{|c|}{ Intervention B } & \multicolumn{4}{|c|}{ Intervention C } & \multicolumn{4}{|c|}{ Reference } \\
\hline & \multicolumn{2}{|c|}{$\begin{array}{l}\text { Baseline } \\
(\mathrm{N}=127)\end{array}$} & \multicolumn{2}{|c|}{$\begin{array}{c}\text { Follow-up } \\
(\mathrm{N}=129)\end{array}$} & \multicolumn{2}{|c|}{$\begin{array}{l}\text { Baseline } \\
(\mathrm{N}=246)\end{array}$} & \multicolumn{2}{|c|}{$\begin{array}{l}\text { Follow-up } \\
(\mathrm{N}=193)\end{array}$} & \multicolumn{2}{|c|}{$\begin{array}{c}\text { Baseline } \\
(\mathrm{N}=95)\end{array}$} & \multicolumn{2}{|c|}{$\begin{array}{c}\text { Follow-up } \\
(\mathrm{N}=86)\end{array}$} & \multicolumn{2}{|c|}{$\begin{array}{l}\text { Baseline } \\
(\mathrm{N}=336)\end{array}$} & \multicolumn{2}{|c|}{$\begin{array}{l}\text { Follow-up } \\
(\mathrm{N}=325)\end{array}$} \\
\hline & Mean & $\mathrm{SD}$ & Mean & SD & Mean & SD & Mean & SD & Mean & SD & Mean & SD & Mean & SD & Mean & $\mathrm{SD}$ \\
\hline Need for recovery & 1.77 & 0.66 & 1.64 & 0.70 & 1.73 & 0.77 & 1.56 & 0.66 & 1.41 & 0.68 & 1.55 & 0.74 & 1.73 & 0.71 & 1. & 0.72 \\
\hline Disturbed sleep index & 2.60 & 0.76 & 2.65 & 0.80 & 2.60 & 0.78 & 2.74 & 0.73 & 2.64 & 0.87 & 2.68 & 0.75 & 2.60 & 0.78 & 2.56 & 0.82 \\
\hline Awakening index & 2.42 & 0.73 & 2.46 & 0.83 & 2.31 & 0.81 & 2.41 & 0.71 & 2.25 & 0.87 & 2.27 & 0.95 & 2.40 & 0.76 & 2.36 & 0.83 \\
\hline Somatic symptoms & 1.64 & 0.48 & 1.69 & 0.55 & 1.75 & 0.55 & 1.64 & 0.48 & 1.71 & 0.55 & 1.69 & 0.51 & 1.73 & 0.57 & 1.76 & 0.55 \\
\hline Mental distress & 1.74 & 0.54 & 1.79 & 0.59 & 1.88 & 0.58 & 1.75 & 0.54 & 1.81 & 0.59 & 1.81 & 0.63 & 1.84 & 0.64 & 1.89 & 0.64 \\
\hline
\end{tabular}

vention B did not include a time bank, and it was only possible to choose between a number of predefined types of duties. In intervention $\mathrm{C}$, a time bank was included, but it was still only possible to choose between a number of predefined duties. Furthermore, the workplace in intervention $\mathrm{C}$ did not require 24 -hour staffing. Thus the possibilities to influence working hours were higher in intervention A than interventions B and C.

Hypothesis 1a stating that implementation of selfrostering is followed by changes in objective workplace reports of working hours was partially supported. Concerns have been raised that self-rostering would lead to compressed work schedules because shift workers prefer many consecutive days off $(17,21)$. We did not observe systematic changes in this direction, as we did not observe an increase in sequences with $>6$ consecutive work days and $>3$ consecutive days off. Kecklund et al (21) found that police officers evaluated a rapidly rotating shift system more positively than compressed shift systems with rapid rotating and frequent quick returns, but a higher number of days off. This is, however, in contrast to another study, where it was found that police officers with self-rostering both had more long periods with four consecutive days off and also more often chose to have only one day off compared to a rapidly rotating shift system (29). The difference is likely to be due to the difference in reference group between the two studies.

It is also recommended in the literature to have a maximum of three consecutive night shifts, few early morning shifts, a limited number of consecutive workdays and quick returns, and to limit weekend work (22, $23,30)$. Implementation of self-rostering did not compromise these recommendations.

Hypothesis $1 \mathrm{~b}$ stating that implementation of self-rostering is followed by increased self-reports of influence on 
Table 4. Effect of intervention on workplace reports of working hours. Interaction term [intervention (int)×time] expresses extent to which outcome at follow-up in interventions A and B differ significantly from what would have been expected from (i) the baseline difference between each of the intervention and reference groups (intervention effect) and from (ii) difference between baseline and follow-up level in the reference group (time effect). Adjusted for age and gender, Bold indicates significance. [OR=odds ratio; $95 \% \mathrm{Cl}=95 \%$ confidence interval]

Number of dayshifts per 4 weeks Number of evening shifts per 4 weeks Number of night shifts per 4 weeks Number of shifts $\leq 4$ hours

Number of shifts $\geq 9$ hours

Number of shifts $\geq 12$ hours

Single workdays

$\geq 6$ consecutive days

Affected weekends

Saturday plus Sunday work

Single day off

$>3$ consecutive days off

$>4$ consecutive night shifts

Quick returns

Hours/week (hours)

Variation (hours)

Mean shift length (hours)

\begin{tabular}{|c|c|c|c|c|c|c|c|c|c|c|}
\hline \multicolumn{4}{|c|}{ Intervention A } & \multicolumn{4}{|c|}{ Intervention B } & \multicolumn{3}{|c|}{ Overall P-value a } \\
\hline OR & $\beta$ & $95 \% \mathrm{Cl}$ & $P$-value ${ }^{b}$ & OR & $\beta$ & $95 \% \mathrm{Cl}$ & $P$-value ${ }^{b}$ & Int & Time & Intxtime \\
\hline 0.99 & & $0.68-1.45$ & 0.961 & 1.41 & & $1.01-1.96$ & 0.044 & $<0.001$ & 0.011 & 0.079 \\
\hline 1.38 & & $0.99-1.93$ & 0.056 & 1.07 & & $.79-1.45$ & 0.649 & 0.010 & 0.002 & 0.159 \\
\hline 0.90 & & $0.61-1.32$ & 0.584 & 0.88 & & $0.64-1.21$ & 0.425 & 0.014 & 0.776 & 0.702 \\
\hline 4.81 & & $1.87-12.3$ & 0.001 & 0.69 & & $0.26-1.82$ & 0.455 & 0.015 & 0.062 & $<0.001$ \\
\hline 4.78 & & $2.85-8.02$ & $<.0001$ & 1.45 & & $0.97-2.18$ & 0.072 & $<0.001$ & $<0.001$ & $<0.001$ \\
\hline 0.90 & & $0.48-1.68$ & 0.7 & 0.86 & & $0.52-1.43$ & 0.5 & $<0.001$ & $<0.001$ & 0.846 \\
\hline 1.48 & & 89-2.47 & 0.13 & 0.97 & & 0.61 & & 0.651 & 0.371 & 0.251 \\
\hline 0.83 & & -1.73 & & 1.7 & & & & 0.0 & 0.707 & 0.251 \\
\hline 1.51 & & 2.40 & & 1.0 & & & & & 0.042 & 0.232 \\
\hline 1.79 & & & & & & & & 01 & 001 & 0.076 \\
\hline 0.96 & & & & 1.4 & & & & & 0.8 & 0.243 \\
\hline 0.65 & & 1.05 & 0.07 & 1.2 & & & & $<0.0$ & 0.883 & 0.035 \\
\hline 1.00 & & -1.79 & 0.98 & 1.0 & & 2.02 & & 0.030 & 0.832 & 1.000 \\
\hline 1.02 & & $0.60-1.75$ & 0.942 & 1.13 & & $0.71-1.79$ & 0.615 & 0.080 & 0.223 & 0.876 \\
\hline & 0.23 & $-1.58-2.04$ & 0.804 & & 0.62 & $-0.96-2.20$ & 0.442 & $<0.001$ & 0.342 & 0.743 \\
\hline & -0.19 & $-0.33--0.04$ & 0.011 & & -0.10 & $-0.22-0.02$ & 0.10 & $<0.001$ & 0.013 & 0.030 \\
\hline & 0.69 & 0.21-1.17 & 0.005 & & -0.30 & $-0.72-0.12$ & 0.158 & $<0.001$ & $<0.001$ & 0.001 \\
\hline
\end{tabular}

a Overall P-value for the intervention, time and the interaction term interventionxtime.

${ }^{b}$ P-value for pairwise post-hoc analysis comparing the effect of the interaction term for A and B with reference.

Table 5. Effect of intervention on self-reports of various factors. Interaction term [intervention (int)xtime] expresses extent to which outcome at follow-up in interventions A, B, and C differ significantly from what would have been expected from (i) the baseline difference between each of the intervention and reference groups (intervention effect) and from (ii) difference between baseline and follow-up level in the reference group (time effect). Adjusted for age and gender, Bold indicates significance. [OR=0dds ratio; $95 \% \mathrm{Cl}=95 \%$ confidence

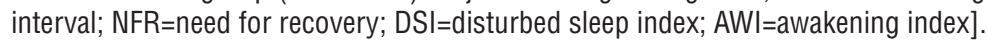

\begin{tabular}{|c|c|c|c|c|c|c|c|c|c|c|c|c|c|c|c|}
\hline & \multicolumn{4}{|c|}{ Intervention A } & \multicolumn{4}{|c|}{ Intervention B } & \multicolumn{4}{|c|}{ Intervention C } & \multicolumn{3}{|c|}{ Overall P-value a } \\
\hline & $\mathrm{OR}$ & $\beta$ & $95 \% \mathrm{Cl}$ & P-value ${ }^{b}$ & $\mathrm{OR}$ & $\beta$ & $95 \% \mathrm{Cl}$ & P-value ${ }^{b}$ & OR & $\beta$ & $95 \% \mathrm{Cl}$ & P-value ${ }^{b}$ & Int & Time & Intxtime \\
\hline $\begin{array}{l}\text { Influence } \\
\text { on working } \\
\text { hours }\end{array}$ & 3.86 & & $2.34-6.37$ & $<0.0001$ & 2.43 & & $1.64-3.61$ & $<0.0001$ & 0.75 & & $0.46-1.23$ & 0.259 & $<0.001$ & $<0.001$ & $<0.001$ \\
\hline $\begin{array}{l}\text { Preferred } \\
\text { length of } \\
\text { duty }\end{array}$ & 7.07 & & $4.13-12.1$ & $\mid<0.0001$ & 1.27 & & $0.85-1.89$ & 0.248 & 2.17 & & $1.28-3.67$ & 0.004 & $<0.001$ & $<0.001$ & $<0.001$ \\
\hline Time of day & 6.43 & & $3.69-11.2$ & $<<0.0001$ & 1.27 & & $0.83-1.93$ & 0.268 & 1.65 & & $0.93-3.92$ & 0.085 & $<0.001$ & $<0.001$ & $<0.001$ \\
\hline $\begin{array}{l}\text { What day to } \\
\text { work }\end{array}$ & 6.96 & & $3.76-12.9$ & $<0.0001$ & 2.48 & & $1.63-3.78$ & $<0.0001$ & 1.89 & & $1.07-3.33$ & 0.028 & $<0.001$ & $<0.001$ & $<0.001$ \\
\hline $\begin{array}{l}\text { Satisfaction } \\
\text { with working } \\
\text { hours }\end{array}$ & 2.50 & & $1.43-4.39$ & 0.001 & 1.38 & & $0.90-2.12$ & 0.142 & 0.36 & & $0.21-0.63$ & $<0.0001$ & 0.764 & 0.010 & $<0.001$ \\
\hline Change job & 0.82 & & $0.47-1.43$ & 0.477 & 0.68 & & $0.43-1.07$ & 0.098 & 2.93 & & $1.42-6.03$ & 0.004 & 0.161 & 0.567 & 0.003 \\
\hline NFR & & -0.165 & $-0.29--0.04$ & 0.010 & & -0.170 & $-0.27--0.065$ & 0.002 & & 0.037 & $-0.101-0.18$ & 0.599 & 0.001 & 0.507 & 0.001 \\
\hline DSI & & 0.081 & $-0.076-0.23$ & 0.309 & & 0.169 & $0.037-0.30$ & 0.012 & & 0.141 & $-0.032-0.31$ & 0.110 & 0.874 & 0.382 & 0.070 \\
\hline AWI & & 0.072 & $-0.083-0.23$ & 0.363 & & 0.095 & $-0.035-0.23$ & 0.151 & & 0.042 & $-0.128-0.21$ & 0.627 & 0.118 & 0.919 & 0.518 \\
\hline $\begin{array}{l}\text { Somatic } \\
\text { symptoms }\end{array}$ & & 0.020 & $-0.078-0.12$ & 0.686 & & -0.104 & $-0.19--0.022$ & 0.013 & & -0.073 & $-0.18-0.034$ & 0.180 & 0.110 & 0.897 & 0.036 \\
\hline $\begin{array}{l}\text { Mental } \\
\text { distress }\end{array}$ & & 0.037 & $-0.081-0.16$ & 0.542 & & -0.131 & $-0.23--0.032$ & 0.010 & & -0.061 & $-0.19-0.063$ & 0.356 & 0.044 & 0.535 & 0.025 \\
\hline
\end{tabular}


working hours was confirmed for all intervention groups. In contrast, satisfaction with working hours increased in intervention $\mathrm{A}$, but decreased in intervention $\mathrm{C}$. The main purpose of implementation of self-rostering in intervention $\mathrm{C}$ was to optimize the use of staff resources in relation to the needs of the company. In interviews, employees also reported that simultaneously with implementation of self-rostering, working hours had shifted towards more shifts in the late afternoon. Together with the 45-minute time buffer (see description of intervention C) and a decrease in the possibilities to swap duties after the schedule had been published, the flexibility at the discretion of the employer had therefore increased. Such changes motivated or dictated by organizational interests have been found to have equivocal or negative health effects (14). It is therefore likely that these differences at least to some degree explain the decreased satisfaction with working hours in intervention $\mathrm{C}$.

Hypothesis 1c stating that implementation of selfrostering resulted in improved recovery and health could be confirmed in intervention $\mathrm{B}$, whereas we were surprised to find that only need for recovery decreased in intervention $\mathrm{A}$. We expected intervention $\mathrm{A}$ to have the largest impact, since it included more possibilities to change working hours. However, other results from the same study indicated that some employees in intervention $\mathrm{A}$ found that the intervention had negative consequences for: private life; the relation to customers, clients, and patients; and the quality of the work as well as collaboration at the workplace, whereas this was not the case in intervention B (33). There were no significant deteriorations of recovery, sleep, and health. Overall, we therefore add further evidence to strengthen the tentative conclusion of Joyce et al (14) that interventions that increase worker control and preference over working hours are likely to have a positive effect on health outcomes (14), but also that some interventions may be more effective than others.

There were no improvements of recovery and health in intervention $\mathrm{C}$, which may be related to the fact that they did not have night work where most of the shift work problems, related to for example sleep, occur (1, 2). Furthermore, the employees in intervention $\mathrm{C}$ were used to knowing their schedules months in advance, and in interviews they expressed frustration over the reduced predictability of having new schedules published with only 4-week notice. In interventions $\mathrm{A}$ and $\mathrm{B}$, employees were used to having new schedules with a 4-week notice and here the increased influence was considered more of a benefit. Another issue is that employees in interventions $\mathrm{A}$ and $\mathrm{B}$ had some influence on working hours in terms of the preferences being considered before the introduction of self-rostering. It may be speculated that the effects of self-rostering would be even larger in these groups if such influence had not been present at baseline.
We could not confirm hypothesis $2 \mathrm{a}$, which stated that changes in health were mediated through changes in working hours. All together, we found most improvements in health in intervention B despite that there were no statistically significant changes in working hours. In contrast, influence on working hours increased the most in intervention $\mathrm{A}$, but the only health-related effect was a decrease in need for recovery. This indicates that a major part of the effects of self-rostering on health were due to other aspects of the intervention than changes in working hours. It may be that increases in perceived personal control play an important role for the effects (19). Another possible explanation is that our measures of working hours were not sufficiently sensitive. For example, we did not distinguish between working on a Wednesday rather than a Monday although this potentially affects how the schedule fits with the employees' preferences.

We also could not confirm hypothesis $2 \mathrm{~b}$, which suggested that the effect of the intervention differed between groups of individuals according to gender, age, family type, and working hour arrangements. Correspondingly, Moen et al (10) found that gender, age, or family-life stage did not affect the effects of larger worktime control and flexibility among white-collar workers. Thus, all groups of employees regardless of age, gender, family type, degree of employment, and working hour arrangement appear to benefit equally from the intervention.

\section{Strengths and limitations}

A strength of the intervention study is its size and the fact that it was performed at several workplaces in various companies. The study design included a reference group allowing us to distinguish between change and effect (28), and we used a Bonferroni reduction in the significance level as well as adjustment for age and gender in all statistical models. The use of objective workplace reports of working hours and descriptions of the interventions also strengthened the study. Thereby we reduced the risk of common method bias. Since salaries are based on the used working hour information, the quality of these data is expected to be high.

Data on working hours were limited to 28 days, and it may be questioned whether they are representative of the working hours throughout the year. The use of daily working hours allowed us to extract several working hour characteristics related to the guidelines on shift scheduling published in the literature. Due to the large variation in the working hours, it was, however, not pertinent (or possible) to assess whether shifts rotated forwards or backwards. There were some differences in working hour characteristics between the groups at baseline. The number of day shifts, night shifts, and 
number of shifts lasting $>12$ hours were more evenly distributed between employees in intervention $\mathrm{B}$ (fewer had 0 , and more had some). This may have given more room in intervention A for increased variation in shift length and timing. Lastly, there may be many reasons for choosing irregular shifts: one may be economical compensation. Unfortunately, we did not collect data on how changes in working hours affected pay and were, therefore, not able to study this.

\section{Concluding remarks}

In this large, longitudinal intervention study on selfrostering, employees changed shift length and timing, when offered the opportunity, but did not compromise most recommendations for design of acceptable shift work schedules. Positive consequences of self-rostering for recovery and health were observed, particularly in intervention B, where influence had increased, but to a lesser extent than intervention A. The effect could not be statistically explained by changes in actual working hours.

\section{References}

1. Åkerstedt T. Shift work and disturbed sleep/wakefulness. Occup Med 2003 Mar;53(2):89-94. http://dx.doi.org/10.1093/ occmed/kqg046.

2. Pilcher JJ, Lambert BJ, Huffcutt AI. Differential effects of permanent and rotating shifts on self-report sleep length: a meta-analytic review. Sleep 2000 Mar 15;23(2):155-63.

3. Wirtz A, Nachreiner F. The effects of extended working hours on health and social well-being--a comparative analysis of four independent samples. Chronobiol Int 2010 Jul;27(5):1124-34. http://dx.doi.org/10.3109/07420528.2010.490099.

4. Pryce J, Albertsen K, Nielsen K. Evaluation of an open-rota system in a Danish psychiatric hospital: a mechanism for improving job satisfaction and work-life balance. J Nurs Manag 2006 May;14(4):282-8. http://dx.doi.org/10.1111/ j.1365-2934.2006.00617.x.

5. Lowden A, Åkerstedt T. Einführung selbst gewählter arbeitszeiten im einzelhandel [Introduction of self-selected work hours in retail work - effects on work satisfaction, health and social life]. Z Arb Wiss 2000;54(5):300-5.

6. Smith L, Hammond T, Macdonald I, Folkard S. 12-h shifts are popular but are they a solution? Int J Indust Ergonomics 1998;21:323-31. http://dx.doi.org/10.1016/ S0169-8141(97)00046-2.

7. Costa G, Akerstedt T, Nachreiner F, Baltieri F, Carvalhais J, Folkard S, et al. Flexible working hours, health, and wellbeing in Europe: some considerations from a SALTSA project. Chronobiol Int 2004;21(6):831-44. http://dx.doi.org/10.1081/ CBI-200035935.
8. Ala-Mursula L, Vahtera J, Kouvonen A, Väänänen A, Linna A, Pentti J, et al. Long hours in paid and domestic work and subsequent sickness absence: does control over daily working hours matter? Occup Environ Med 2006 Sep;63(9):608-16. http://dx.doi.org/10.1136/oem.2005.023937.

9. Vahtera J, Laine S, Virtanen M, Oksanen T, Koskinen A, Pentti J, et al. Employee control over working times and risk of cause-specific disability pension: the Finnish Public Sector Study. Occup Environ Med 2010 Jul;67(7):479-85. http:// dx.doi.org/10.1136/oem.2008.045096.

10. Moen P, Kelly EL, Hill R. Does Enhancing Work-Time Control and Flexibility Reduce Turnover? A Naturally Occurring Experiment. Soc Probl 2011 Feb 1;58(1):69-98. http://dx.doi. org/10.1525/sp.2011.58.1.69.

11. Garde AH, Nabe-Nielsen K, Aust B. Influence on working hours among shift workers and effects on sleep quality An intervention study. Appl Ergon. 2011;42(2):238-43. http://dx.doi.org/10.1016/j.apergo.2010.06.011.

12. Nabe-Nielsen K, Garde AH, Diderichsen F. The effect of worktime influence on health and well-being: a quasi-experimental intervention study among eldercare workers. Int Arch Occup Environ Health 2011;84(6):683-95. http://dx.doi.org/10.1007/ s00420-011-0625-8.

13. Jansen NWH, Kant IJ, Kristensen TS, Nijhuis FJN. Antecedents and consequences of work-family conflict: a prospective cohort study. J Occup Environ Med 2003;45(5):479-91. http:// dx.doi.org/10.1097/01.jom.0000063626.37065.e8.

14. Joyce K, Pabayo R, Critchley JA, Bambra C. Flexible working conditions and their effects on employee health and wellbeing. Cochrane Database Syst Rev 2010;2:1-89.

15. Nabe-Nielsen K, Garde AH, Albertsen K, Diderichsen F. The moderating effect of work-time influence on the effect of shift work: a prospective cohort study. Int Arch Occup Environ Health 2011;84(5):551-9. http://dx.doi.org/10.1007/s00420010-0592-5.

16. Gareis KC, Barnett RC. Under what conditions do long work hours affect psychological distress? A study of full-time and reduced hours female doctors. Work Occup 2002;29(4):48397. http://dx.doi.org/10.1177/0730888402029004005.

17. Nabe-Nielsen K, Kecklund G, Ingre M, Skotte J, Diderichsen $\mathrm{F}$, Garde AH. The importance of individual preferences when evaluating the associations between working hours and indicators of health and well-being. Appl Ergon 2010 Jan 29;41(6):779-86. http://dx.doi.org/10.1016/j. apergo.2010.01.004.

18. Rotter JB. Internal versus external control of reinforcement: A case history of a varible. Am Psych 45[4], 489-493. 1990. http://dx.doi.org/10.1037/0003-066X.45.4.489.

19. Smith L, Iskra-Golec I. Internal locus of control and shiftwork effects. Theoret Issues Ergon Sci 2003;4(3-4):327-39. http:// dx.doi.org/10.1080/14639220210158871.

20. Bandura A. Self-efficacy. The exercise of control. New York: WH Freeman \& Co; 1998

21. Kecklund G, Eriksen CA, Akerstedt T. Police officers attitude to different shift systems: association with age, present 
shift schedule, health and sleep/wake complaints. Appl Ergon 2008 Sep;39(5):565-71. http://dx.doi.org/10.1016/j. apergo.2008.01.002.

22. Knauth P, Hornberger S. Preventive and compensatory measures for shift workers. Occup Med (Lond) 2003 Mar;53(2):109-16. http://dx.doi.org/10.1093/occmed/ kqg049.

23. Wedderburn A. Instruments for designing, implementing and assessing working time arrangements. Luxemburg: European Foundation fot the Improvement of Living and Working Conditions; 1994. Report No: 7.

24. De Croon EM, Sluiter JK, Frings-Dresen MHW. Need for recovery after work predicts sickness absence: a 2-year prospective cohort study in truck drivers. J Psychosom Res 2003 Oct;55(4):331-9. http://dx.doi.org/10.1016/S00223999(02)00630-X.

25. De Croon EM, Sluiter JK, Frings-Dresen MH. Psychometric properties of the Need for Recovery after work scale: test-retest reliability and sensitivity to detect change. Occup Environ Med 2006 Mar;63(3):202-6. http://dx.doi.org/10.1136/ oem.2004.018275.

26. Åkerstedt T, Knutsson A, Westerholm P, Theorell T, Alfredsson L, Kecklund G. Sleep disturbances, work stress and work hours: a cross-sectional study. J Psychosom Res 2002 Sep;53(3):741-8. http://dx.doi.org/10.1016/S00223999(02)00333-1.

27. Steinmetz H, Schmidt P. Subjective health and its relationship with working time variables and job stressors: Sequence or general factor model? Work Stress 2010;24(2):159-78. http:// dx.doi.org/10.1080/02678373.2010.489784.

28. Kristensen TS. Intervention studies in occupational epidemiology. Occup Environ Med 2005 Mar;62(3):205-10. http://dx.doi.org/10.1136/oem.2004.016097.

29. Eriksen CA, Kecklund G. Sleep, sleepiness and health complaints in police officers: the effects of a flexible shift system. Ind Health 2007 Apr;45(2):279-88. http://dx.doi. org/10.2486/indhealth.45.279.

30. Wilson JL. The impact of shift patterns on healthcare professionals. J Nurs Manag 2002 Jul;10(4):211-9. http:// dx.doi.org/10.1046/j.1365-2834.2002.00308.x.

31. Wirtz A, Nachreiner F, Rolfes K. Working on Sundays-effects on safety, health, and work-life balance. Chronobiol Int 2011 May;28(4):361-70. http://dx.doi.org/10.3109/07420528.201 1.565896 .

32. Barnes-Farrell JL, vies-Schrils K, McGonagle A, Walsh B, Milia LD, Fischer FM, et al. What aspects of shiftwork influence off-shift well-being of healthcare workers? Appl Ergon 2008 Sep;39(5):589-96. http://dx.doi.org/10.1016/j. apergo.2008.02.019.

33. Hvid H, Garde AH, Lund H, Ajslev J, Møller J, Albertsen $\mathrm{K}$, et al. Frit valg som aflastning og belastning - selvvalgt arbejdstid i døgnbemandet arbejde. [Self-rostering in shift work]. Tidsskrift for arbejdsliv 2011;13(3):80-97.

Received for publication 31 October 2011 